\title{
Pengaruh Media Pembelajaran Edukatif dalam Pembelajaran Pendidikan Jasmani terhadap Keterampilan Motorik Dasar Siswa Sekolah Dasar
}

Vicki Ahmad Karisman ${ }^{1}$

${ }^{1}$ Program Studi Pendidikan Jasmani Kesehatan dan Rekreasi STKIP Pasundan

\begin{tabular}{l}
\hline Info Artikel \\
SejarahArtikel: \\
Diterima September 2018 \\
Disetujui September 2018 \\
Dipublikasikan Oktober 2018 \\
\\
Keywords: \\
Median....................................... \\
didikan Jasmani, Ketrempilan Motor- \\
ik Dasar
\end{tabular}

didikan Jasmani, Ketrempilan Motorik Dasar

\begin{abstract}
Abstrak
Tujuan penelitian ini adalah untuk mengetahui pengaruh media pembelajaran edukatif dalam pemebelajaran pendidikan jasmani terhadap keterampilan motoric dasar siswa sekolah dasar. Metode penelitian yang digunakan adalah metode eksperimen dengan desain Randomize Pretest-Posttest Control Group Design. Populasi penelitian ini adalah siswa kelas IV di Kota Cimahi, dengan teknik sampling menggunakan cluster random sampling. Penelitian ini dilaksanakan selama 16 kali pertemuan. Teknik pengumpulan data pada penelitian ini menggunakan Test Gross Motor Development - Second Edition (TGMD-2nd Edition) dari Ulrich. Dengan Analisis data menggunakan SPSS 17 dengan urutan analisis data menggunakan Uji T Paired Samples. Adapun hasil penelitian ini adalah terdapat pengaruh yang signifikan dari media pembelajaran edukatif dalam pemebelajaran pendidikan jasmani terhadap keterampilan motorik dasar siswa sekolah dasar.
\end{abstract}

\begin{abstract}
The purpose of this research is to investigate the effect of educational learning media in physical education toward fundamental motor skills of elementary school students. Its used experiment design method with pretest-posttest randomize control group design. The population of this research is four grade elemtary school students in Cimahi, through cluster random sampling. This research was conducted for 16 times treatment. Data collection techniques using Test Gross Motor Development - Second Edition (TGMD-2nd Edition) of Ulrich. Data analysis using SPSS 17 with sequence data analysis using paired samples t-test. The results show that there is a significant effect of educational learning media in physical education toward fundamental motor skills to elementary school students.
\end{abstract}




\section{PENDAHULUAN}

Bergerak seharusnya menjadi kebutuhan. Gerak merupakan dasar dari aktivitas jasmani yang dilakukan oleh manusia, termasuk anakanak untuk menjalani kehidupannya. Aktivitas jasmani yang dilakukan anak-anak berupa berjalan, melompat, berlari, melempar, menendang, memanjat dan lain sebagainya. Selain itu pula dilakukan dalam bentuk permainan baik permainan kecabangan olahraga maupun permainan tradisional.

Anak-anak dapat melakukan aktivitas jasmani dengan baik jika didukung dengan kemampuan gerak dasar yang baik. Ketermapilan gerak dasar adalah pola gerakan yang melibatkan bagian tubuh yang berbeda seperti kaki, lengan, batang dan kepala, dan mencakup keterampilan seperti berlari, melompat, menangkap, melempar, menyerang, dan menyeimbangkan. Keterampilan gerak dasar adalah gerakan pondasi atau pola prekusor untuk keterampilan yang lebih khusus dan kompleks yang digunakan dalam bermain, permainan, olahraga, tari, senam, outdoor education, dan kegiatan fisik rekreasi. Penguasaan keterampilan gerak dasar yang baik akan memudahkan seseorang dalam melakukan berbagai aktivitas fisik. Departemen of Education (2013) . Adapun keterampialn gerak dasar ini terbagi menjadi tiga kategori yaitu body management, lokomotor dan object control.

Penyelenggaraan pembelajaran penjas di SD diarahkan pada penguasaan aspek gerak motorik. Seperti yang dijelaskan oleh National Association for Sport and Physical Education (2011), yang memaparkan bahwa, "In the elementary grades, the physical education program emphasizes the development of fundamental locomotor, non-locomotor, and manipula tive skills through the main content areas of educational games, dance, aquatic and gymnastics". Namun, kenyataannya kemampuan motorik pada siswa SD kemampuan motorik kelas IV SD dapat dikategorikan sedang. Persentase klasifikasi kriteria kemampuan motorik siswa yaitu kategori baik sekali 5.04\%, kategori baik 24,37\%, kategori sedang 39,50\%, kategori kurang $24,37 \%$, dan kategori kurang sekali 6,72\% (Wicaksono \& Nurhayati,2013)

Kemampuan motorik pada siswa akan mempengaruhi berbagai aktivitas gerak yang akan dilakukan. Semakin baik perkembangan motoriknya maka seorang anak dapat memperagakan berbagai keterampilan kecabangan olahraga. Sebaliknya jika perkembangan morik siswa kurang maka mereka akan kesulitan dalam memperagakan berbagai keterampilan kecabanganya. Masalah yang sering terjadi ketika seorang kurang memiliki keterampilan kcabangan olaharaga adalah menjadi fasif dalam aktivitas fisik (Fadilah \& Wibowo, 2018).

Kurang gerak akan menimbulkan terhambatnya kemampuan gerak dasar. Ini menjadi pememicu kurangnya minat anak dalam melakukan aktivitas fisik. kurang terampilnya memperagakan berbagai teknik yang diperlukan menjadi penyebab tidak mampu mengikuti aktivitas fisik. Sehingga yang terjadi adalah enggan melakukan bahkan tidak mau melakukan aktivitas fisik. Kurangnya aktivitas fisik berhubungan dengan kelebihan berat badan, kurang sehat secara fisik, dan tingkat kolesterol yang lebih tinggi.

Obesitas pada masa anak-anak dapat meningkatakan kejadian diabetes melitus (DM) tipe 2. Selain itu, juga beresiko untuk menjadi 
oibesitas pada saat dewasa dan berpotensi mengakibatkan gangguan metabolisme glukosa dan penyakit degeneratif seperti penyakit jantung, penymbatan pembuluh darah dan lainlain. Obesitas pada anak usia 6-7 tahun juga dapat menurunkan tingkat kecerdasan karena aktivitas dan kreativitas anak menjadi menurun dan cenderung malas akibat kelebihan berat badan (Sartika, 2011). Hal ini menunjukan bahwa kurangnya gerak dapat mengancam kesehatan di masa depan. Dengan melakukan aktivitas fisik yang sesuai dan berkelanjutan dapat mengurangi resiko tersebut. Sehingga perlu di desain suatu pembelajaran yang menyenangkan sesuai dengan pertumbuhan dan perkembangan siswa .

Pengemasan pengajaran aktivitas fisik bagi siswa SD harus disesuaikan dengan karakteristiknya. Prinsip pengajaran pendidikan jasmani untuk perkembangan motorik siswa yaitu harus memperhatikan tingkat pertumbuhan, perkembangan dan karakteristik siswa (Williams, dalam Nonies \& Jernice, 2014). Salah satunya siswa SD memili karakteristik Homo Luden, artinya seorang yang suka bermain. Bermain bagi anak-anak merupakan sasaran utama dimana mereka belajar tentang tubuh dan kemampuan motorik mereka (Gallahue ,2006) . Selain itu, bermain juga dapat memberikan manfaat bagi kognitif, fisik, dan emosi anak, seperti yang diungkapkan oleh Stork and Sanders (2008) bahwa "Play is important part of early childhood physical activity. It is essential to development because it contributes to the cognitive, physical, social, and emotional well-being of children and youth." Penelitian Akbari, dkk (2009:123) mengungkap bahwa, "Traditional game program is appropriate for a fundamental motor skill develop- ment". Oleh karena itu, agar keterampilan motorik dasar siswa SD meningkat secara efektif, program pembelajaran tersebut harus melalui permainan

Pencapaian tujuan pembelajaran penjas khususnya keterampilan motorik dasar melalui permainan untuk siswa SD perlu dukungan media yang baik, yaitu media yang mampu menarik minat siswa, sesuai dengan kurikulum yang diterapkan dan mengikuti perkembangan zaman (Taufik\&Pardijono, 2013). Penggunaan media pembelajaran dapat berpengaruh hasil belajar yang dicapai siswa. Penggunaan media audio visual dapat meningkatan hasil belajar penjas yang signifikan (Jaliusril, dkk, 2012). Media pembelajaran penjas berfungsi untuk memfasilitasi komunikasi yang terjadi antara guru dan siswa dalam proses belajar mengajar penjas. Menurut Caspy \& Gorsky (2005) menyebutkan bahwa fungsi media yaitu, " (1) to provide immediate feedback, (2) to transmit verbal and non verbal communication cues, (3) to provide a sense of personalization and (4) to simulate natural language". Salah satu fungsi media ini adalah untuk menyampaikan komunikasi secara verbal dan non verbal. Print media, Chalks and Chalkboard, Graphic Materials, Realia, Still Pictures, Models and MockUps, Audio Media, Overhead Projectors, Slide Projectors and Filmstrip Projector, Film Projector and Video Player/Projector, Multi-Media Presentation (Onasanya, 2010:128) adalah berbagai macam media yang dapat digunakan dalam pengajaran penjas.

$$
\text { Penelitian Maibach }
$$
mengungkap bahwa, "We must invest in better understanding the nature and impact of media's temptation as it pertains to physical activity. We will be wise, however, to focus those invest- 
ments both to better understand the problem, and to better cultivate media's potential as part of the solution". Sesuai dengan hasil penelitian ini, pengajajaran penjas yang dikemas melalui media permainan edukatif diharapkan dapat menjadi solusi untuk mengembangkan keterampilan motorik dasar siswa SD.

\section{METODE PENELITIAN}

Pelaksanaan penelitian ini akan dilaksanakan di dua Sekolah Dasar (SD) di Kota Cimahi. Penelitian ini akan dilaksanakan mulai dari tahap persiapan penelitian sampai penyusunan laporan penelitian pada bulan January 2017 sampai dengan Desember 2017.

Populasi dari penelitian ini adalah seluruh siswa SD kelas IV di Kota Cimahi. Alasan Populasi di SD kelas IV adalah karena menurut Long Term Athlete Development (LTAD) Canadian Sport for Life (2012) menyebutkan bahwa Karakteristik siswa kelas 4 Sekolah Dasar dengan usia 7-10 tahun dikatakan sebagai Fundamental movement skills. Pengambilan sampel dalam penelitian ini yaitu dengan cara cluster random sampling.

Metode penelitian untuk mengungkap pengaruh media permainan edukatif terhadap keterampilan motorik dasar siswa SD adalah metode penelitian True Eksperimen dengan desain Randomize Pretest-Posttest Control Group Design (Fraenkel, 2012). Dalam penelitian ini, kelompok control tetap dilakukan treatment media permainan edukatif lempar sehat. Pelaksanaan penelitian ini dilaksanakan selama 4 bulan dari bulan Februari 2017 hingga April 2017 dengan rincian 1 pertemuan untuk melakukan observasi awal di lapangan tentang penggunaan media pembelajaran penjas, melakukan perencanaan penelitian dengan membuat program permainan menggunakan media permainan edukatif ular tangga dan lempar sehat, mempersiapkan dan membuat media permainan edukatif ular tangga dan lempar sehat. Untuk perlakuan dilakukan selama dua bulan mulai bulan Maret 2017 sampai April 2017 dengan 1 pertemuan untuk pengambilan data pre-test, 16 kali pertemuan yang dilaksanakan setiap 2 kali seminggu, data post-test diambil pada pertemuan ke-16. Berikut adalah langkah-langkah yang dilakukan dalam penelitian eksperimen menggunakan media permainan edukatif dalam pembelajaran penjas untuk keterampilan motorik siswa SD dengan tahapan penelitian sebagai berikut:

\section{Pre-test}

Pretes dilakukan kepada kelompok eksperimen dan kelompok kontrol. Instrumen yang digunakan adalah Test of Gross Motor Development - Second Edition (TGMD-2) yang dikembangkan oleh Ulrich (2000).

\section{Treatment}

Treatment yang digunakan pada sampel kelompok eksperimen dalam penelitian ini adalah media permainan edukatif ular tangga dan lempar sehat. (treatment) dilakukan selama dua bulan mulai bulan Maret 2017 sampai April 2017 dengan 2 kali pertemuan setiap minggunya selama 16 kali pertemuan. Berikut merupakan rancangan program pengajaran penjas melalui media permainan edukatif ular tangga dan lempar sehat untuk keterampilan motorik dasar siswa. 
Tabel 1 Materi pengajaran penjas menggunakan media permainan edukatif ular tangga dan lempar sehat

\begin{tabular}{|c|c|}
\hline $\begin{array}{l}\text { Waktu } \\
\text { Pertemuan }\end{array}$ & $\begin{array}{l}\text { Materi Penjas menggunakan media } \\
\text { permainan edukatif ular tangga } \\
\text { dan lempar sehat }\end{array}$ \\
\hline Pre Test & Tes TGMD \\
\hline Pertemuan $1 \& 2$ & Berjalan \& Berlari \\
\hline Pertemuan $3 \& 4$ & Lempar \& Tangkap \\
\hline Pertemuan $5 \& 6$ & Lompat \& Loncat \\
\hline Pertemuan $7 \& 8$ & Galloping \& Hopping \\
\hline Pertemuan $9 \& 10$ & Leaping \& Sliding \\
\hline Pertemuan $11 \& 12$ & Memukul \& menendang \\
\hline Pertemuan $13 \& 14$ & Dribling \& Rolling \\
\hline Pertemuan $15 \& 16$ & Festival keterampilan motorik dasar \\
\hline Post Test & Tes TGMD \\
\hline
\end{tabular}

\section{Post-test}

Pelaksanaan posttest sama dengan pelaksanaan pretest, namun posttest dilakukan setelah semua kelompok baik kelompok yang diberikan media permainan edukatif ular tangga maupun lempar sehat diberi perlakuan. Tes menggunakan tes TGMD.

Teknik pengumpulan data pada penelitian ini Test Gross Motor Development Second Edition (TGMD-2nd Edition) dari Ulrich (2000). Analisis data menggunakan SPSS 17.

\section{HASIL PENELITIAN}

Nilai hasil uji Paired Samples Test pada data hasil pre tes dan post test keterampilan motorik dasar menunjukan nilai signifikansi sebesar 0,018. Karena signifikansi pada data pre test dan post test keterampilan motorik dasar $<0,05$ maka hasil penelitian menunjukan bahwa terdapat pengaruh yang signifikan dari media pembelajaran edukatif dalam pemebelajaran
Tabel 2. Uji Paired Samples Test

Paired Samples Test

\begin{tabular}{|c|c|c|c|c|c|c|c|c|}
\hline & \multicolumn{5}{|c|}{ Paired Differences } & \multirow[b]{3}{*}{$\mathrm{t}$} & \multirow[b]{3}{*}{ df } & \multirow{3}{*}{$\begin{array}{l}\text { Sig. } \\
(2- \\
\text { taile } \\
\text { d) }\end{array}$} \\
\hline & \multirow[b]{2}{*}{ Mean } & \multirow{2}{*}{$\begin{array}{l}\text { Std. } \\
\text { Dev }\end{array}$} & \multirow{2}{*}{$\begin{array}{l}\text { Std. } \\
\text { Error } \\
\text { Mean }\end{array}$} & \multicolumn{2}{|c|}{$\begin{array}{l}95 \% \text { Confidence } \\
\text { Interval of the } \\
\text { Difference }\end{array}$} & & & \\
\hline & & & & Lower & Upper & & & \\
\hline Pair 1 & & & & & & & & \\
\hline $\begin{array}{l}\text { Pre_eks - } \\
\text { Post_eks }\end{array}$ & -6.85 & 9.47 & 2.53 & -12.3 & -1.38 & -2.7 & 13 & .000 \\
\hline
\end{tabular}

penjas terhadap keterampilan motorik dasar siswa sekolah dasar.

Hal ini dapat terjadi karena. Keterampilan motorik dasar salah satunya dapat dipengaruhi oleh kesesuaian pengajaran yang dilakukan guru, artinya guru harus memperhatikan karakteristik siswa SD, tingkat pertumbuhan dan juga perkembangannya. Sejalan dengan ini, penelitian Barela (2013:548) mengungkap bahwa, "Motor development is influenced by many factors such as practice and appropriate instruction, provided by teachers". Salah satu karakteristik siswa SD adalah Homo Luden, artinya seorang yang suka bermain. Gallahue (2006:29) menyatakan bahwa "Bermain bagi anak-anak merupakan sasaran utama dimana mereka belajar tentang tubuh dan kemampuan motorik mereka". Pengemasan pembelajaran penjas dalam rangka meningkatkan keterampilan motorik dasar siswa SD hendaknya dikemas dengan permainan, namun harus tetap menonjolkan sisi edukatifnya, yaitu adanya proses belajar siswa.

Sejalan dengan ini, Goodway, dkk (2009:289) mengungkapkan bahwa, "The findings from this study support the notion that fundamental motor skills must be taught and practiced if children are to learn". Media menunjukkan fungsi atau perannya, yaitu mengatur hubungan yang efektif antara dua pihak utama 
dalam proses belajar, siswa dan isi pelajaran (Nugrahani, 2007:36). Dengan menggunakan media yang tepat maka siswa akan belajar dengan menyenangkan dan keterampilan motoriknya dapat berkembang.

\section{KESIMPULAN}

Media pembelajaran edukatif dalam pemebelajaran penjas dapat meningkatkan keterampilan motorik dasar siswa sekolah dasar.

\section{DAFTAR PUSTAKA}

Akbari, Hakimeh, dkk. 2009. The Effect of Traditional Games in Fundamental Motor Skill Development in 7-9 Year Old Boys. Iran Jurnal Pediatr. Vo.19 (2), h.123-129.

Angelo Barela, José. 2013. Fundamental motor skill proficiency is necessary for children's motor activity inclusion. Motriz, Rio Claro, vol.19 (3),h. 548-551.

Capsi, Avner \& Gorsky, Paul. 2006. Instructional Media Choice: Factors Affecting the Preferences of Distance Education Coordinators. Journal of Educational Multimedia and Hypermedia14 (2), h.169-198

Delas, dkk. 2008. The Influence Of Motor Factors On Performing Fundamental Movement Skills - The Differences Between Boys And Girls. Physical Education and Sport Vol. 6 (1), h. $31-39$.

Departement of Education. 2013. Fundamental Movement Skill : Learning, Teaching, and Assesment Preparing Children For An Active and Helathy Lifestyle. ISBN: 978-0-73074524-2. Australia

Elviana, dkk. 2010. Permainan Edukatif dengan menggunakan media karpet dam-dam terhadap gerak dasar melompat. FKIP UNTAN.

Fadilah, M., \& Wibowo, R. (2018). Kontribusi Keterampilan Gerak Fundamental Terhadap Keterampilan Bermain Small-Sided Handball Games. JURNAL PENDIDIKAN JASMANI DAN OLAHRAGA, 3(1), 60-68.

Freankel, Jack R, dkk. (2012). How to Design and Evaluate Research in Education. New York: McGraw Hill.Children Moving. A Reflective
Approach to Teaching Phyisical Education. California: Mayfield Publishing Company.

Gallahue, David L. (2006). Developmental Physical Education for Today's Children (third edition). USA: Brown \& Benchmark Publisher.

Goodway, dkk. 2006. Effects of Motor Skill Instruction on Fundamental Motor Skill Development. Adapted Physical Activity Quarterly, Vo.1. 20 (3) h. 298-314.

Griffiths, Gillian\& Billard, Rebecca. 2013. The Fundamental Movement Skills of a Year 9 Group and a Gifted and Talented Cohort. Advances in Physical Education. Vol.3, (4), h. 215-220.

Hands, Beth. 2010. How can we best measure Fundamental Movement Skills?. Notherdam: School of Health and Physical Education.

Husdarta, J. S dan Yudha M. Saputra. 2013. Belajar dan Pembelajaran Pendidikan Jasmani dan Kesehatan. Bandung: Alfabeta.

Jaliusril,dkk. 2012. Pengembangan Media AudioVisual Pembelajaran Lari Jarak Pendek Untuk Siswa Smp. Tekno Pedagogi. Vo. 2 (1) h. 1-21.

Maibach, Edward. 2007. The Influence of the Media Environment on Physical Activity: Looking for the Big Picture. Journal of Science Health Promotion. Vol. 21, (4). H1. 352-362.

Malik, Arif Abdul. 2013. Ular Tangga Olahraga Media Permainan Edukatif Untuk Olahraga Dengan Menggunakan Sistem Sirkuit Training Bagi Siswa Kelas X Sma. Journal of Physical Education, Sport, Health and Recreation 2 (10), h. 630-636.

Nonis, Karen \& Jernice Ye. 2014. The Gross Motor Skills Of Children With Mild Learning Disabilities. International Journal Of Special Education. Vol 29 (2), h. 1-6.

Rahina, Nugrahani. 2007. Media Pembelajaran Berbasis Visual Berbentuk Permainan Ular Tangga untuk Meningkatkan Kualitas Belajar Mengajar di Sekolah Dasar. Semarang: Jurusan Seni Rupa-Fakultas Bahasa dan Sastra Universitas Negeri Semarang.

Santrock, J.W. (2006). Life Span Development (5th ed) : Perkembangan Masa Hidup jilid 1. Jakarta : Erlangga.

Sartika, D Ayu Ratu. 2011. Faktor Resiko Obesitas pad Anak 5-15 Tahun di Indonesia. Jurnal Marka, Kesehatan, Vol. 15, No. 1, Juni 2011: 37-43. Universitas Indonesia.

Taufik \& Pardijono. 2013. Efektivitas Pembelajaran Pendidikan Jasmani Di Sma Negeri Surabaya Tentang Pemanfaatan Sarana Dan Prasarana. 
Vicki Ahmad Karisman / Journal of Teaching Physical Education in Elementary School 2 (1) (2018)

Jurnal Pendidikan Olahraga dan Kesehatan. Vol. 01 (02) h. $392-399$.

Ulrich. 2000. Test Gross Motor Development - Second Edition (TGMD-2nd Edition).

Wicaksono, Didik Cahyo \& Nurhayati, Faridha. Survey Kemampuan Motorik Siswa Sekolah Dasar Muhammadiyah Kelas Iv Se-Kecamatan Taman Sidoarjo Tahun Ajaran 2012 -2013. Jurnal Pendidikan Olahraga dan Kesehatan Vol. 01 (01) h. $98-103$ 